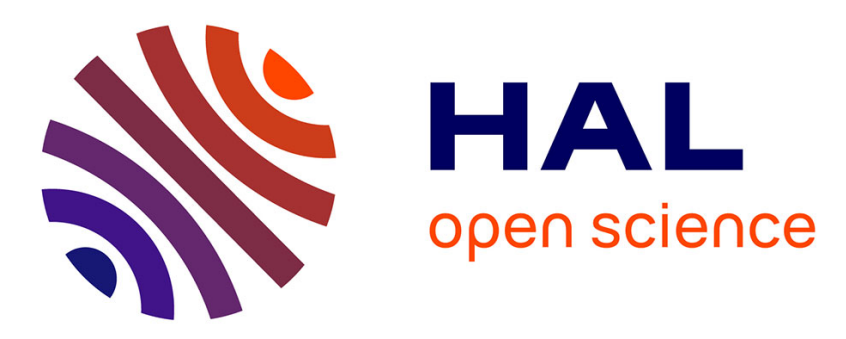

\title{
Optimization by calculation method of pulsed-arc welding modes using high alloy welding material
}

A V Zavdoveev, V D Poznyakov, O A Gaivoronskyi, A M Denysenko, T Baudin

\section{- To cite this version:}

A V Zavdoveev, V D Poznyakov, O A Gaivoronskyi, A M Denysenko, T Baudin. Optimization by calculation method of pulsed-arc welding modes using high alloy welding material. $\quad=$ The Paton Welding Journal, 2021, 10.37434/tpwj2021.04.02 . hal-03384880

\section{HAL Id: hal-03384880 \\ https://hal.science/hal-03384880}

Submitted on 19 Oct 2021

HAL is a multi-disciplinary open access archive for the deposit and dissemination of scientific research documents, whether they are published or not. The documents may come from teaching and research institutions in France or abroad, or from public or private research centers.
L'archive ouverte pluridisciplinaire HAL, est destinée au dépôt et à la diffusion de documents scientifiques de niveau recherche, publiés ou non, émanant des établissements d'enseignement et de recherche français ou étrangers, des laboratoires publics ou privés. 


\title{
OPTIMIZATION BY CALCULATION METHOD OF PULSED-ARC WELDING MODES USING HIGH ALLOY WELDING MATERIAL
}

\author{
A.V. Zavdoveev ${ }^{1}$, V.D. Poznyakov ${ }^{1}$, O.A. Gaivoronskyi ${ }^{1}$, \\ A.M. Denysenko ${ }^{1}$ and T. Baudin ${ }^{2}$ \\ ${ }^{1}$ E.O. Paton Electric Welding Institute of the NAS of Ukraine \\ 11 Kazymyr Malevych Str., 03150, Kyiv, Ukraine \\ ${ }^{2}$ Université Paris-Saclay, CNRS, Institut de Chimie Moléculaire et des matériaux d'Orsay \\ 91405 Orsay, France
}

\begin{abstract}
The use of modern pulsed-arc welding technologies allows a significant improvement of the quality of welded joints. However, a large number of possible welding modes hinder the development and implementation of pulse technologies in modern production. This is associated with the fact that in pulsed-arc welding at least four independently variable parameters exist, which in totality requires a large number of experiments to determine their impact. To optimize the number of experiments in this study, the experimental calculation Taguchi algorithm for the process of pulsating arc welding using a high alloy welding material was implemented. The quantitative contribution of each variable welding parameter in the formation of the penetration depth is shown. The optimal welding modes were proposed, providing a set penetration depth. 15 Ref., 6 Tables, 4 Figures.
\end{abstract}

Ke y w o r d s : pulsating arc welding, penetration depth, Taguchi algorithm, high alloy welding material

\section{Introduction}

Pulsed-arc welding (PAW) is qualitatively different from traditional welding in shielding gases [14]. This is predetermined by expanded capabilities of PAW in affecting the processes of melting and transfer of the electrode metal, formation of the structure in the weld and HAZ metal of welded joint, regulating the weld shape, penetration depth, etc. Today, this method of welding is increasingly used in world practice in the manufacture of critical welded structures from highstrength steels [4-7].

At present, the leading companies developed many inverter welding current sources based on pulse tech-nologies for MIG/MAG welding. Thus, the Swedish Company Esab developed the power source Aristo 500, the American Company Hobart - Ultra-Arc 350, the German Company EWM Phoenix 501 pulse. Due to a wide range of tasks that can be solved in PAW, they are in demand in the domestic production of critical metal structures. However, it should be noted that these sources have built-in programs with a wide range of modes, from which it is difficult to choose the optimal one for a specified variant of welding.

In PAW, there are four variable mode parameters: base current (Ib), pulse current (IP), frequency (f), and duty cycle $(\mathrm{C})$. Therefore, while choosing a mode, it is necessary to conduct a large number of experi-ments. Also, a well-known experimental calculation Taguchi method exists [8], which allows evaluating the influence of each of the parameters of a mode on welded joint formation.

The aim of the work was to make the selection of PAW modes using the Taguchi method, which provide a set penetration depth of the $\mathrm{V}$-shaped groove without a gap of a butt joint of high-strength alloy steel with a reverse weld formation with the use of a high-alloy welding material. 


\section{Experimental procedure}

When performing the investigations, the parameters of PAW by pulsating arc were selected, which are given in Table 1.

Table 1. Selected parameters for PAW

\begin{tabular}{|c|c|c|c|c|c|c|c|}
\hline \multirow{3}{*}{ Parameter } & \multirow{3}{*}{ Note } & \multicolumn{6}{|c|}{ Level } \\
\hline & & \multicolumn{3}{|c|}{ Value } & \multicolumn{3}{|c|}{ Coding } \\
\hline & & Minimum & Mean & Maximum & Minimum & Mean & Maximum \\
\hline Pulse current, A & $\mathrm{A}$ & 160 & 200 & 240 & 1 & 2 & 3 \\
\hline Pause current, A & $\mathrm{B}$ & 80 & 120 & 140 & 1 & 2 & 3 \\
\hline Frequency, $\mathrm{Hz}$ & $\mathrm{C}$ & 0.5 & 1 & 5 & 1 & 2 & 3 \\
\hline Duty cycle, $\%$ & $\mathrm{D}$ & 40 & 60 & 80 & 1 & 2 & 3 \\
\hline
\end{tabular}

In the mentioned experiment there are four independently controlled process parameters and three experimental levels. In full, for four factors and three levels it would be necessary to conduct a $3^{4}=81$ experiment. The method proposed by Taguchi uses orthog-onal arrays (OAs) for determination of the minimum number of experiments in real time to evaluate all de-signing factors. In such an experimental scheme, each factor is evaluated individually and one does not affect the other. The conditions that emerged in this study, i.e. four parameters together with their three levels, are suitable for the selection of the L9 matrix as an experi-mental project. Table 2 presents nine experimental tests in real time, which were compiled as specified in the scheme L9 $\left(3^{4}\right)$ according to the Taguchi method $[8$, 9]. In this case, the experiments should be carried out in random order to bypass noise sources.

Table 2. Performance of tests on the base of designing plan

\begin{tabular}{|c|c|c|c|c|c|c|c|c|}
\hline \multirow{2}{*}{ Number } & \multicolumn{2}{|c|}{ Pulse current, A } & \multicolumn{2}{c|}{ Pause current, A } & \multicolumn{2}{c|}{ Frequency, Hz } & \multicolumn{2}{c|}{ Duty cycle, \% } \\
\cline { 2 - 9 } & Value & Code & Value & Code & Value & Code & Value & Code \\
\hline 1 & 160 & 1 & 80 & 1 & 0.5 & 1 & 40 & 1 \\
\hline 2 & 160 & 1 & 120 & 2 & 1 & 2 & 60 & 2 \\
\hline 3 & 160 & 1 & 140 & 3 & 5 & 3 & 80 & 3 \\
\hline 4 & 200 & 2 & 80 & 1 & 1 & 2 & 80 & 3 \\
\hline 5 & 200 & 2 & 120 & 2 & 5 & 3 & 40 & 1 \\
\hline 6 & 200 & 2 & 140 & 3 & 0.5 & 1 & 60 & 2 \\
\hline 7 & 240 & 3 & 80 & 1 & 5 & 3 & 60 & 2 \\
\hline 8 & 240 & 3 & 120 & 2 & 0.5 & 1 & 80 & 3 \\
\hline 9 & 240 & 3 & 140 & 3 & 1 & 2 & 40 & 1 \\
\hline
\end{tabular}

Calculation of signal-to-noise ratio. When conducting experiments, different process parameters are used, which give different values of «response». As a «response», penetration depth (PD) was chosen. In the course of experimental tests, it was necessary to evaluate the influence of each selected factor with the help of the received «responses», which may not be unique and have both desirable and undesirable characteristics. According to the Taguchi method, the signal/noise ratio ( $S /$ $N$ ) is a deviation of the qualitative characteristic from the desired value. During calculation of the $\mathrm{S} / \mathrm{N}$ ratio, one should choose among the three available operating values - a higher, a lower and a nominal one (HB, LB and NB). 
The calculation of the $S / N$ ratio was performed according to the equation (1). The generalized calculated $S / N$ ratios for all experiments are presented in Table 3.

$$
\frac{S}{N}=-10 \log \left(\frac{\sum_{1}^{n} \frac{1}{Y^{2}}}{n}\right) .
$$

Table 3. Results of measuring penetration depth and signal-to-noise ratio

\begin{tabular}{|c|c|c|c|c|c|c|c|}
\hline \multirow{2}{*}{ Number } & \multicolumn{4}{|c|}{ Parameters } & \multicolumn{2}{|c|}{ Response } & \multirow{2}{*}{$Q / V, \mathrm{~kJ} / \mathrm{mm}$} \\
\hline & Pulse current, A & Pause current, A & Frequency, Hz & Duty cycle, $\%$ & $\mathrm{PD}$ & $S / N$ & \\
\hline 1 & 160 & 80 & 0.5 & 40 & 0.88 & -1.128 & 0.42 \\
\hline 2 & 160 & 120 & 1 & 60 & 2.159 & 6.673 & 0.55 \\
\hline 3 & 160 & 140 & 5 & 80 & 2.47 & 7.851 & 0.61 \\
\hline 4 & 200 & 80 & 1 & 80 & 3.37 & 10.55 & 0.68 \\
\hline 5 & 200 & 120 & 5 & 40 & 3.31 & 10.4 & 0.62 \\
\hline 6 & 200 & 140 & 0.5 & 60 & 2.091 & 6.374 & 0.72 \\
\hline 7 & 240 & 80 & 5 & 60 & 2.926 & 9.322 & 0.67 \\
\hline 8 & 240 & 120 & 0.5 & 80 & 3.597 & 11.12 & 0.93 \\
\hline 9 & 240 & 140 & 1 & 40 & 3.349 & 10.5 & 0.75 \\
\hline
\end{tabular}

The next step in the analysis consists in dividing the influence of each individual parameter on all three considered levels and ranking them in the order of their influence on the response parameter. This is possible because the selected experimental scheme corresponds to the orthogonal L9 matrix [10].

The average efficiency of the factor is calculated by dividing the sum of the test results including the factor by a number of the tests performed at the same level (equation (2)):

$$
\text { for example, }\left\langle S / N>_{A 1}=\left(S / N_{1}+S / N_{2}+S / N_{3}\right) / 3\right.
$$

Contribution of individual factors to the penetration depth. Rated control of the final answer requires knowledge of the degree of contribution of individual process parameters, and they can be evaluated using a statistical method, namely ANOVA [11]. In the ANOVA methodology, SS, SS', $D, V$ and $P$ are typical symbols of the parameters, used in the above mentioned analysis to represent the factors, sum and adjusted sum of squares, degree of freedom, dispersion and a percentage contribution of each factor, respectively $[12,13]$. A brief explanation of the abovementioned factors is presented below.

The total sum of SST squares can be calculated from the S/N ratio from the equation (3), which uses the terms «total number of experiments $(\mathrm{m}=9)$ )» and «i-th current signal-to-noise ratio $\eta \mathrm{i}$ :

$$
S S_{T}=\sum_{i=1}^{9} S / N_{i}^{2}-\frac{1}{9}\left(\sum_{i=1}^{9} S / N_{i}\right)^{2} .
$$

The total sum of $S S_{T}$ squares can be calculated from the $S / N$ ratio from the equation (3), which uses the terms «total number of experiments $(m=9)$ » and «i-th current signal-to-noise ratio $\eta$ : 
The sum of squares of factors, denoted as $S S_{p}$ is calculated by the equation (4), which has the follow-ing conditions: factor «p», number of its level as « $j »$, repetition of each level for the tested factor $\mathrm{p}$, as «t» $(=3)$, summation of the signal-to-noise $(S / N)$ ratio, that connects this coefficient $p$ and its level $j$ as $S / N p j=\left(S / N_{1}+S / N_{2}+S / N_{3}\right)$ for the level $A_{j}=1,\left(S / N_{2}+S / N_{3}+S / N_{4}\right)$ for the level $A_{j}=2,\left(S / N_{7}+S / N_{8}+S / N_{9}\right)$ for the level $A_{j}=3$.

$$
S S_{P}=\sum_{j=1}^{3} \frac{\left(\sum S / N p j\right)^{2}}{3}-\frac{1}{9}\left(\sum_{i=1}^{9} S / N_{i}\right)^{2} .
$$

The degree of freedom (DOF) is one of the elements that should be taken into account when calculating ANOVA [11]. $D_{p}$ and $V_{p}$ are the notations used to represent the degree of freedom and the dispersion of the factor $p$. $V_{p}$ is determined as a percentage with the use of $S S_{p}$ from $D_{p}$ in accordance with the equation (5).

$$
V_{p}(\%)=\frac{S S_{p}}{D_{p}} \cdot 100 .
$$

The summation of DOF, accompanied near the tests and the mean value, is called the total DOF. The degree of freedom for the mean value is always equal to 1 . Therefore, the total degree of freedom for this experimental study is 8 , which is equal to the number of tests ( 9 tests) -1 , and the degree of freedom for the parameters is 2 , which is obtained by subtracting 1 from the number of parameter levels (3 levels).

The difference between SSp (sum of squares of factors) and the product of the dispersion of errors and DOF of each test factor is called the adjusted sum of squares and is denoted as SSp which is calculated by the equation (6).

$$
S S_{P}^{\prime}=S S_{P}-D_{P} V_{e}
$$

The percentage ratio of the tested factors between their corrected sum and the total sum of squares is called their percentage contribution and is denoted as $P_{p}$. The equation (7) is used to determine $P_{p}$ :

$$
P_{p}(\%)=\frac{S S_{P}^{\prime}}{S S_{T}} \cdot 100
$$

\section{Results and discussion}

Macrosections of the deposits produced in accordance with the program (Table 2) are shown in Figure 1, where the number corresponds to the surfacing mode. The results of the calculation of the penetration depth for the mentioned specimens are given in Table 3. Using the Taguchi algorithm, taking into account the corresponding values of the signal-to-noise ratio, the mean values for each level and welding parameter are calculated, which are given in Table 4.

As is seen from the calculations, pulse current for penetration depth parameter is ranked by the number «1», which indicates that it has the greatest influence on penetration depth than on pause current, frequency and duty cycle.

The ANOVA results provide information on the quantitative contribution of each parameter. 

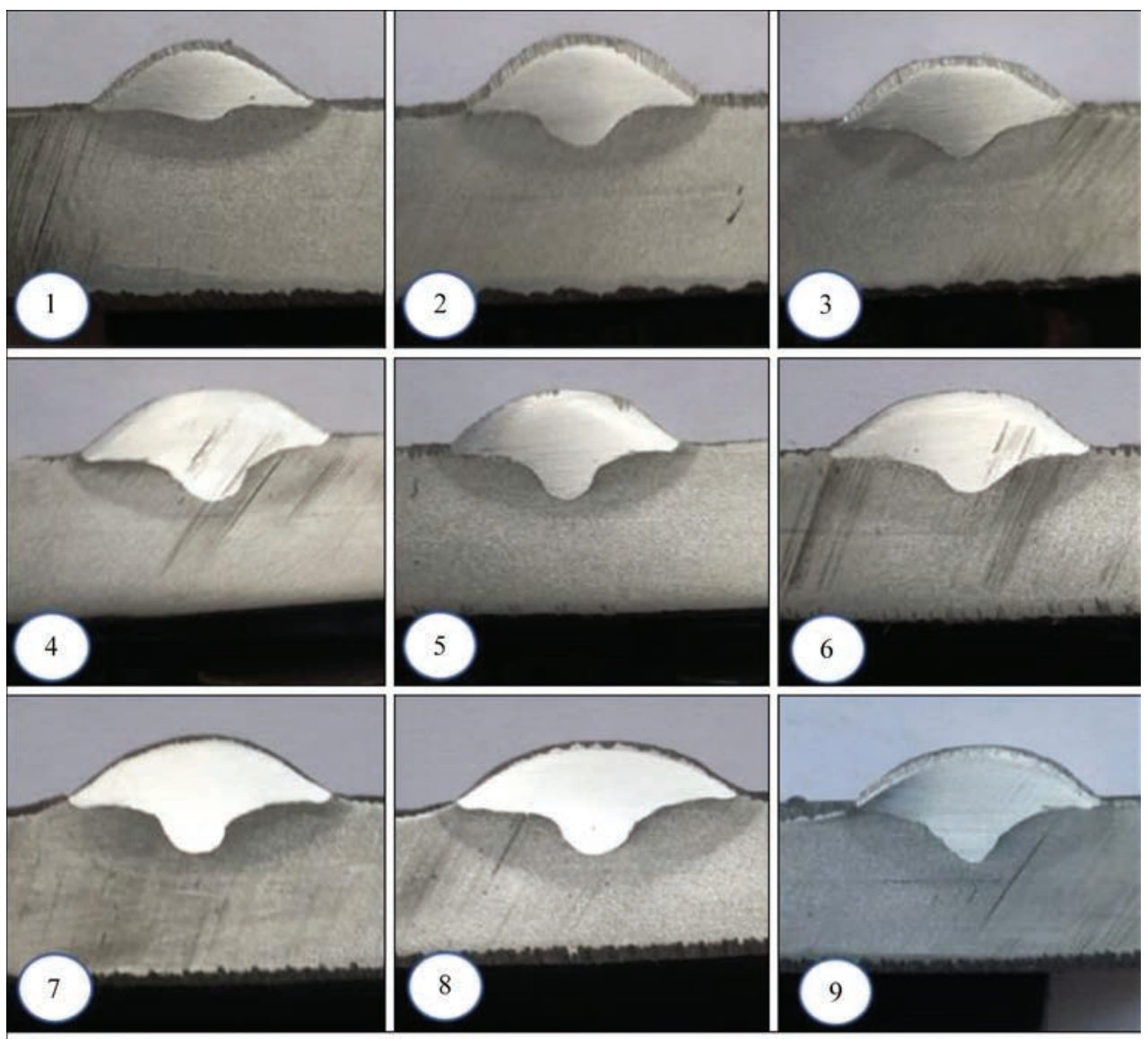

$10 \mathrm{~mm}$

Figure 1. Photo of macrosections of experimental deposits

Table 4. Calculation of $S / N$ values according to the algorithm of Taguchi

\begin{tabular}{|c|c|c|c|c|c|c|}
\hline Parameter & Note & Level 1 & Level 2 & Level 3 & $\Delta=\max$-min & Rank \\
\hline Pulse current, A & A & 4.465 & 9.107 & 10.31 & 5.85 & 1 \\
\hline Pause current, A & B & 6.249 & 9.395 & 8.241 & 3.15 & 4 \\
\hline Frequency, Hz & C & 5.454 & 9.24 & 9.189 & 3.79 & 2 \\
\hline Duty cycle, \% & D & 6.588 & 7.456 & 9.84 & 3.25 & 3 \\
\hline
\end{tabular}

Compliance test for checking repeatability. After selecting the optimal level of designing process parameters, this is a mandatory step to determine and check the improvement of quality characteristics with the use of the optimal level of designing parameters. According to [11-15], the predicted signal-to-noise ratio for the optimal level of the design process pa-rameters can be calculated as:

$$
\hat{\eta}=\eta_{m}+\sum_{i=1}^{n}\left(\bar{\eta}_{i}-\eta_{m}\right)
$$




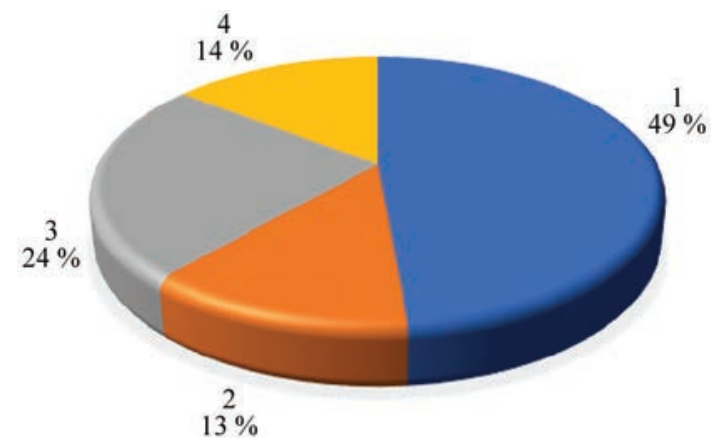

Figure 2. Results of calculations by ANOVA method: 1 - pulse current; 2 - pause current; 3 -frequency; 4 - duty cycle

In the above mentioned equation, $\eta_{m} \eta_{i}$ and $n$ represent the mean $S / N$ ratio (Table 4 ) and the total number of important projects of experimental parameters affecting the quality. The predicted $S / N$ ratio can be found using the optimal parameters of the pulsating arc welding process (Tables 5, 6).

Table 5. Results of evaluating the predicted number and confirming the results for the optimal state of the PA-GMAW process (PD is the maximum)

\begin{tabular}{|c|c|c|c|c|c|c|}
\hline & & & & & \multicolumn{2}{|c|}{ S/N } \\
\cline { 4 - 6 } Parameters & $\mathrm{A}$ & $\mathrm{B}$ & $\mathrm{C}$ & $\mathrm{D}$ & $\begin{array}{c}\text { Predic- } \\
\text { tion }\end{array}$ & $\begin{array}{c}\text { Experi- } \\
\text { ment }\end{array}$ \\
\hline $\begin{array}{c}\text { Optimal coded } \\
\text { value }\end{array}$ & 3 & 2 & 2 & 3 & \multirow{2}{*}{14.9} & 12.04 \\
\hline Optimal value & 240 & 120 & 1 & 80 & & \\
\hline Deviation $=19 \%$.
\end{tabular}

Table 6. Results of evaluating the predicted number and confirming the results for the optimal state of the PA-GMAW process ( $\mathrm{PD}$ is the minimum)

\begin{tabular}{|c|c|c|c|c|c|c|}
\hline & & & & & \multicolumn{2}{|c|}{ S/N } \\
\cline { 4 - 6 } Parameters & $\mathrm{A}$ & $\mathrm{B}$ & $\mathrm{C}$ & $\mathrm{D}$ & $\begin{array}{c}\text { Predic- } \\
\text { tion }\end{array}$ & $\begin{array}{c}\text { Experi- } \\
\text { ment }\end{array}$ \\
\hline $\begin{array}{c}\text { Optimal coded } \\
\text { value }\end{array}$ & 2 & 1 & 2 & 1 & -1.13 & -1.21 \\
\hline Optimal value & 200 & 80 & 1 & 40 & & \\
\hline \multicolumn{1}{|l}{ Deviation $=7 \%$}
\end{tabular}

The results of checking the predicted welding modes in order to obtain the maximum and minimum penetration depth during pulsating arc welding are shown in Figure 3. As is seen, the experimental-calculation algorithm of Taguchi makes it possible to predict the response of the studied parameter, namely penetration depth with a high accuracy.

The results of the studies were used while selecting the optimal PAW mode for the root layer of the $\mathrm{V}$-shaped joint of high-strength steel, the groove of which was made without a gap and had a $4 \mathrm{~mm}$ blunting (Figure 4). At the same time, it was possible to obtain the proper quality of the welded joint, namely to provide penetra-tion of the groove root with the reverse weld formation already in the course of the first experiment. 


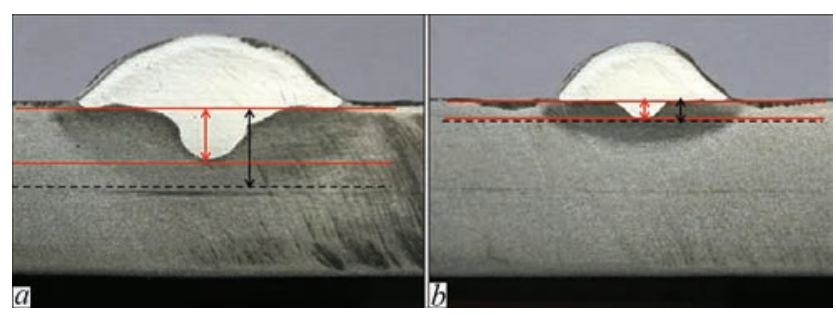

Figure 3. Macrosections of deposits produced according to the calculated modes, with maximum (a) and minimum (b) PD (dotted line shows calculated value of penetration and solid line shows experimental one)

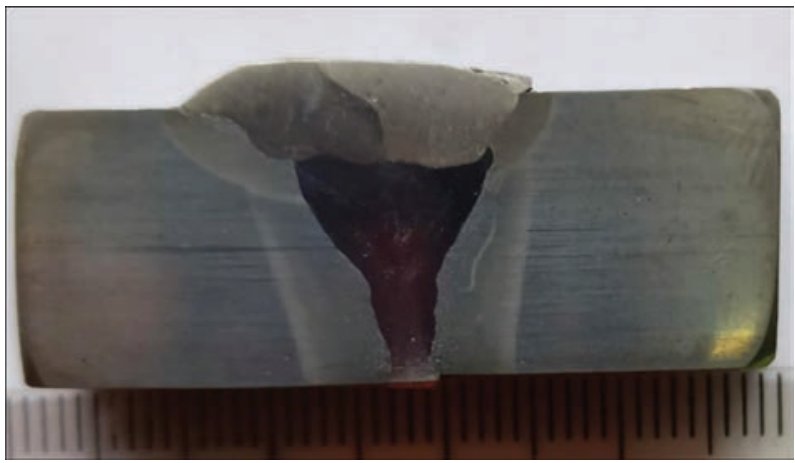

Figure 4. Butt joint of high-strength steel (V-shaped, without a gap, 4 mm blunting)

It should be noted that the Taguchi method can also be used when selecting PAW modes for multilayer joints in order to obtain the optimal HAZ dimensions. This is a very important factor that significantly affects the technological and operational properties of welded joints of critical metal structures made of high-strength alloy heat-hardened steels. The studies in this direction are performed and the results will be presented in future publications.

\section{Conclusions}

1. A study of the influence of pulsed-arc welding modes (welding current, pause current, frequency, duty cycle) on penetration depth using a high-alloy welding wire by means of the experimental calculation Taguchi method was carried out. The possibility of controlling the parameters of pulsating arc welding in order to obtain the required penetration depth in a wide range was shown.

2. It was found that pulse current has a predominant influence on penetration depth. The influence of frequency, duty cycle and pause current is the next in importance. The quantitative analysis revealed that the influence of these parameters is distributed as fol-lows: pulse current - $49 \%$, pause current $13 \%$, frequency - $24 \%$, duty cycle - $14 \%$.

3. The carried out studies allowed proposing the optimal modes of pulsed-arc welding, which provide the set values of penetration depth, namely the minimum and the maximum one. The verification experiment showed that within the limits of insignificant deviations the predicted values of penetration depth correlate with the experimental ones.

4. Experimental calculation Taguchi method is a powerful and promising tool that can be used while selecting the optimal modes and in the development of pulsed-arc welding technologies. 


\section{References}

1. Poznyakov, V.D., Zavdoveev, A.V., Gajvoronsky, O.A. et al.(2018) Effect of pulsed-arc welding modes on the change of weld metal and HAZ parameters of welded joints produced with Sv-08kh20N9G7T wire. The Paton Welding J., 9, 7-12. DOI: https://doi.org/10.15407/tpwj2018.09.02

2. Palani, P.K., Murugan, N. (2006) Selection of parameters of pulsed current gas metal arc welding. J. Mater. Process. Techn., 172, 1-10.

3. Tong, H., Ueyama, T. (2001) Quality and productivity im-provement in aluminium alloy thin sheet welding using alternating current pulsed metal inert gas welding system. Sci. Technol. Weld. Join., 6(4), 203-208.

4. Rajasekaran, S. (1999) Weld bead characteristics in pulsed GMA welding of Al-Mg alloys. Weld. J., 78(12), $397-407$.

5. Zavdoveev, A., Rogante, M., Poznyakov, V. et al. (2020) De-velopment of the PC-GMAW welding technology for TMCP steel in accordance with welding thermal cycle, welding tech-nique, structure and properties of welded joints. Reports in Mechanical Engineering, 1(1), 26-33.

6. Murray, P.E. (2002) Selecting parameters for GMAW using dimensional analysis. Weld. J., 81(7), 125-131.

7. Essers, W.G., Van Gompal. (1984) Arc control with pulsed GMA welding. Ibid., 64(6), 26-32.

8. Ross, P.J. (1988) Taguchi techniques for quality engineering: Loss function, orthogonal experiments, parameter and toler-ance design. New York, McGraw-Hill, 1988 Aug.

9. Phadke, M.S. (1995) Quality engineering using robust design. Prentice Hall PTR, 1995 Dec. 1.

10. Ma, Y, Hu, H, Northwood, D, Nie, X. (2007) Optimization of the electrolytic plasma oxidation processes for corrosion pro-tection of magnesium alloy AM50 using the Taguchi method. J. Mater. Process. Technol., Feb. 182(2), 58-64.

11. Wang, Y, Northwood, DO. (2008) Optimization of the poly-pyrrole-coating parameters for proton exchange membrane fuel cell bipolar plates using the Taguchi method. J. Power Sources, Oct. 15, 185(1), 226-32.

12. Magudeeswaran, G, Balasubramanian, V, Reddy, GM. (2008) Effect of welding processes and consumables on high cycle fatigue life of high strength, quenched and tempered steel joints. Materials \& Design., Oct. 1, 29(9), 1821-7.

13. Yousefieh, M, Shamanian, M, Saatchi, A. (2011) Optimization of the pulsed current gas tungsten arc welding (PCGTAW) parameters for corrosion resistance of super duplex stainless steel (UNS S32760) welds using the Taguchi method. J. Al-loys Compd., Jan. 21, 509(3), 782-8.

14. Do Kim, K, Han, DN, Kim, HT. (2004) Optimization of ex-perimental conditions based on the Taguchi robust design for the formation of nano-sized silver particles by chemical re-duction method. Chem Eng J., Nov. 15, 104, 55-61.

15. Yang WP, Tarng YS. (1998) Design optimization of cutting parameters for turning operations based on the Taguchi meth-od. J. Mater. Process. Technol., Dec. 1, 84, 122-129. 